\title{
COMUNIDADES SUJAS DE LAMA: DA DESTRUIÇÃO À RESSIGNIFICAÇÃO E A RESISTÊNCIA EM MARIANA/MG
}

\author{
COMUNIDADES SUCIAS DE BARRO: DE LA DESTRUCCIÓN A LA \\ RESIGNIFICACIÓN Y LA RESISTENCIA EN MARIANA/MG \\ MUD-DIRTY COMMUNITIES: FROM DESTRUCTION TO \\ RESIGNIFICATION AND RESISTANCE IN MARIANA/MG, BRAZIL
}

\author{
Leticia Cardoso Barreto ${ }^{1}$, Débora Diana da Rosa ${ }^{1}$ e Claudia Mayorga ${ }^{1}$ \\ ${ }^{1}$ Universidade Federal de Minas Gerais, Belo Horizonte/MG, Brasil
}

\begin{abstract}
RESUMO: No dia 5 de novembro de 2015, o rompimento da barragem de rejeitos de Fundão em Mariana-MG (Brasil) de propriedade das mineradoras Samarco, Vale e BHP Billiton destruiu comunidades e contaminou o Rio Doce, sendo reconhecido como o maior desastre/crime sócio ambiental do Brasil. Nosso objetivo neste artigo é compreender os sentidos de comunidade construídos e acessados pelos atingidos dessas localidades anteriormente ao desastre e após o mesmo. Para tal, recorreremos a dados coletados durante diferentes contatos com o campo realizados pelas três autoras e que incluíram a realização de visitas aos territórios, entrevistas com atingidos e atingidas, observação participante (eventos, reuniões, outros), registro em diário de campo. Os resultados apontam que há uma constante busca por tentar recriar o sentimento de comunidade que se mostra principalmente na manutenção do vínculo com o espaço físico devastado e na tentativa de recriar o mesmo no espaço onde será feito o reassentamento.
\end{abstract}

PALAVRAS-CHAVE: Comunidade; Psicologia Social; Mariana/MG.

RESUMEN: El 5 de noviembre de 2015, la ruptura de la presa de relaves Fundão en Mariana-MG (Brasil), propiedad de las compañías mineras Samarco, Vale y BHP Billiton, destruyó comunidades y contaminó el Río Doce, siendo reconocido como el mayor desastre/crimen socioambiental en Brasil. Nuestro objetivo en este artículo es comprender los significados de la comunidad construida y accedida por los afectados en estos lugares antes y después del desastre. Con este fin, utilizaremos los datos recopilados durante los diferentes contactos con el campo llevados a cabo por las tres autoras, que incluyeron visitas a los territorios, entrevistas con los afectados y afectadas, observación participante (eventos, reuniones, otros) y registro en un diario de campo. Los resultados muestran que existe una búsqueda constante para tratar de recrear el sentimiento de comunidad que se muestra principalmente en el mantenimiento del vínculo con el espacio físico devastado y en el intento de recrearlo en el espacio donde se realizará el reasentamiento.

PALABRAS CLAVE: Comunidad; Psicología social; Mariana/MG.

ABSTRACT: On November 5, 2015, the Fundão dam owned by the mining companies Samarco, Vale and BHP Billiton broke in Mariana/MG (Brazil), destroying communities and contaminating the Rio Doce, being recognized as the biggest socio-environmental catastrophe/crime in Brazil. Our goal in this article is to understand the senses of community built and accessed by those affected before and after the disaster. To this end, we used data collected during different field contacts made by the three authors, which included visits to the affected territories, interviews with those affected, participant observation (events, meetings and others), and recording in a field diary. The results indicate that there is a constant search to try to recreate the feeling of community, which is shown mainly in the maintenance of the bond with the devastated physical space and in the attempt to recreate it in the space where the resettlement will be done.

KEYWORDS: Community; Social Psychology; Mariana/MG. 


\section{Introdução}

Cheguei assim sem entender nada, aí à medida que o tempo foi passando eu comecei a entender que eu era um atingido. Ai um dia eu cheguei... eu falei com ele assim, a Samarco tem medido... o quê que é atingido, de acordo com o que a lama sujou a vida, as coisas dele. Ai ele falou virou pra mim e falou assim: não, atingido é aquele que teve a vida suja de lama. Na hora que eu olhei pra mim eu enxerguei... todo tampado de lama dos pés a cabeça.

(Atingido de Paracatu de Baixo)

No dia 5 de Novembro de 2015, o rompimento da barragem de rejeitos de Fundão em Mariana-MG (Brasil) de propriedade das mineradoras Samarco/Vale e BHP Billiton destruiu comunidades e contaminou o Rio Doce de Minas Gerais até o litoral da Bahia, sendo reconhecido como o maior desastre/crime socioambiental do Brasil. Diante de tal fato, temos como objetivo compreender os sentidos da palavra "comunidade", construídos e acessados pelas populações das localidades atingidas antes e depois do desastre, apoiando-nos teoricamente nas contribuições da Psicologia Social Comunitária.

O rompimento da barragem da Samarco, Vale e BHP Billiton em Mariana/MG, despejou mais de 80 milhões de toneladas de resíduos de minério de ferro sobre a bacia do Rio Doce, destruindo casas e plantações, matando animais, ocasionando a morte de 19 pessoas, além de um aborto e, ainda, implicando no deslocamento de pelo menos 360 famílias. De acordo com o relatório do Instituto Brasileiro do Meio Ambiente e dos Recursos Naturais Renováveis (IBAMA), a lama chegou a $663 \mathrm{~km}$ de rios, sendo $77 \mathrm{~km}$ de assoreamento drástico e destruição de 1469 hectares de vegetação, incluindo áreas de preservação permanente (APP).

O rastro da lama causou a destruição das comunidades de Pedras, Camargos, Borba, Ponte do Gama, Campinas, Paracatu de Cima, Paracatu de Baixo e Bento Rodrigues em Mariana. Atingiu a cidade de Barra Longa e seguindo o leito do Rio Doce, chegou às cidades de: Sem Peixe; Rio Doce; Santa Cruz do Escalvado; Rio Casca; São Domingos da Prata; São José do Goiabal; São Pedro dos Ferros; Dionísio; Raul Soares; Córrego Novo; Pingo D’Água; Mariléia; Bom Jesus do Galho; Caratinga; Timóteo; Santana do Paraíso; Bugre; Iapu; Coronel Fabriciano; Ipaba; Ipatinga; Belo Oriente; Naque; Periquito; Sobrália; Fernandes Tourinho; Alpercata; Tumiritinga; Galileia; Conselheiro Pena; Resplendo; Itueta, Aimorés. Ainda, atingiu no Espírito Santo as cidades: Baixo Guandu, Colatina e Linhares, Serra, São Mateus, Aracruz até o litoral da Bahia. Destacamos que mesmo passados mais de quatro anos do rompimento de Fundão, os danos causados ainda são incertos em sua totalidade, podendo existir outras cidades ou comunidades atingidas que não estão contempladas nesta listagem.

Ao longo do caminho de destruição causado pela lama, verifica-se: mortes de trabalhadores da empresa e habitantes das comunidades afetadas, sendo que uma pessoa ainda está desaparecida; despejo de populações; devastação de localidades e consequente desagregação dos laços sociais das comunidades; destruição de estruturas públicas e privadas (edifícios, pontes, ruas, etc.); destruição de áreas agrícolas; interrupção de energia elétrica pelas usinas hidrelétricas afetadas (Candonga, Aimorés e Mascarenhas); destruição de Áreas de Preservação Permanente (APPs) e vegetação nativa da Mata Atlântica; mortalidade da biodiversidade aquática e da fauna terrestre; interrupção da pesca por 
um período indeterminado; interrupção do turismo; perda e fragmentação de habitats; restrição ou fragilidade dos serviços ambientais dos ecossistemas; alteração dos padrões de qualidade das águas frescas, marinhas e salgadas; sensação de perigo e desamparo da população.

O desastre/crime será assim chamado por nós, por entendermos que a nomeação dada à tragédia constitui um campo polissêmico e de disputas de distintas ordens, não só discursivas, mas também no campo social, econômico e político. Logo após, o rompimento de Fundão, as empresas Samarco,Vale e BHP Billiton, se apressaram em classificá-lo como um "acidente", fruto de abalos sísmicos que teriam atingido a região de Mariana. Fato este, descartado ao longo do processo de investigação criminal que encontrou falhas estruturais em Fundão desde o início das suas operações no ano de 2008 e que levaram ao seu colapso. Diante disso, o rompimento é considerado pela polícia civil, um crime, na qual 21 executivos das empresas Samarco, Vale, BHP e a consultoria VogBR foram denunciados por homicídio qualificado com dolo eventual em função da morte de 19 pessoas.

Mesmo com as evidências apontadas na investigação criminal, as empresas no "acordão” (Termo de Transação e Ajustamento de Conduta - TTAC), assinado com os governos federais e estaduais do Espírito Santo e Minas Gerais no ano de 2016, utilizaram o termo "evento" para se referir a tragédia, tentando ao máximo estipular um limite cronológico ao danos causados, restringindo-os ao "dia do evento", em uma clara omissão as graves consequências deixadas pela lama na vida das pessoas atingidas ao longo do tempo em que esperam pelos reassentamentos e indenizações. Cabe enfatizar que as pessoas atingidas rechaçam fortemente o uso desta expressão, por elas vinculada a festividades.

Ainda, surgiram outras nomeações, como "acidente de trabalho com graves repercussões socioambientais", termo cunhado pelo Ministério do Trabalho de Minas Gerais. "Desastre natural”, classificação feita pela então presidenta Dilma Rousseff seis dias após o rompimento de Fundão para que os atingido(a)s pudessem fazer o saque de seu Fundo de Garantia sobre Tempo de Serviço (FGTS). "Desastre tecnológico”, especificação feita por estudiosos e especialistas da área da sociologia dos desastres, que entendem o rompimento de Fundão como sendo efeito da ação e negligência humana, na qual as empresas são responsáveis pelo dano (Zhouri et al., 2016).

Compreendendo que um nome neste caso não é só um nome, e que há também violência nas formas como nomeamos as coisas, neste trabalho, faremos o uso da expressão desastre/crime. Reconhecendo assim o acúmulo dos debates acadêmicos em torno da expressão "desastre tecnológico" e associado à palavra "crime”, em função das formas como os próprios atingidos e atingidas classificam o rompimento de Fundão, como um crime que destruiu suas vidas. Desta forma, reconhecemos a não neutralidade do nosso contato com o campo de intervenção e pesquisas e fazemos uma escolha ética e política de nos posicionarmos ao lado das comunidades na luta por seus direitos.

A partir do crime, pequenas comunidades como Bento Rodrigues e Paracatu passaram a ocupar a mídia e seus antigos habitantes tiveram suas vidas totalmente reviradas e sujas pela lama, seja na perda de suas residências, das possibilidades de trabalho ou de seus vínculos afetivos. O rompimento da barragem acarretou profundos impactos nas vidas das milhares de famílias atingidas que repentinamente perderam as referências socioespaciais e territoriais de suas histórias e memórias. Mais do que a perda de um lugar físico, perdeu-se um lugar simbólico e subjetivo, construído a partir da materialidade no espaço e fortalecido por meio das redes, vínculos e laços sociais, formando uma vida em/na comunidade. 
A destruição física do espaço comunitário, acarreta também impactos sobre a dimensão da história e da memória das famílias, que passam a ter seu território reduzido ao próprio corpo. Suas lembranças, como as fotografias, objetos que pertenceram a outras gerações da família, as paisagens naturais, tudo foi reduzido à lama.

Nos constituímos enquanto sujeitos e, ao mesmo tempo, construímos relações com os outros, dentro de uma dimensão temporal de experiência e existência atrelados a uma dimensão socioespacial. É por meio das relações subjetivas, simbólicas e objetivas que estabelecemos contextos/meios/territórios nos quais nos inserimos e estes arcabouços de referências constroem parte do que somos e, também, constituem parte da nossa história geracional e cultural.

Maurice Halbwachs destaca que a memória coletiva, diferentemente da história, é marcada por uma continuidade constituída por aquilo que é ainda vivo na consciência de um determinado grupo ou coletividade, que retém do passado similitudes que atuam no processo de constituição e manutenção de sua identidade, perpetuando sentimentos e imagens. A memória coletiva é o grupo na perspectiva da própria comunidade, estabelecida por visões que formam de si e de seu passado, ressignificado, que dá sentido e unidade ao mesmo, mas que também reconstrói suas diferenças e mudanças (Halbwachs, 1990).

Mesmo diante de processos de deslocamento obrigatório de um território para outro, essas memórias/histórias compõem as diásporas e ajudam a manter laços e vínculos culturais de dada comunidade.

Ah eu imagino assim... Aí tem hora que eu tento imaginar... aquela praça, da gente ficar a vontade de novo no final de semana, dia domingo... dia domingo, né, a gente fazia almoço no sábado, né?... já ia para a rua. Chegava de noite. No sábado, tinha uma... a gente ficava na rua até certas horas a Sandra não ficava aberto até mais do que 10, $11 \mathrm{~h} . .$. aí tinha festa na rua até meia noite $1 \mathrm{~h}, 2 \mathrm{~h} . .$. ai tinha uma lanchonete pra cima, nós tirava a mulher da lanchonete da cama! Pra nós virar a noite... no bar dela, na lanchonete dela. [Risos] E quando alguém não abria pra nós tinha fogueirinha... Ela ia, ela ia, abria, ah não vou ter sossego pra dormir mesmo. Abria, a gente continuava virava a madrugada, outra hora a gente marcava ah hoje o churrasco vai ser aqui em casa. Ai ocê trazia um quilo de carne, a outra não sei, trazia três cerveja... aí outra hora juntava, uma, vamo levar a carne e vamo fazer uma vaquinha pra cerveja, pra outra bebida

(Atingido de Bento Rodrigues)

Quando as lembranças/laços/vínculos que mantém de certa forma vivas memórias e ajudam a construir comunidades são perdidas de forma tão abrupta - como no caso dos moradores e moradoras de Bento Rodrigues e Paracatu de Baixo que tiveram suas casas, pertences pessoais, fotos, objetos de família destruídos, e até mesmo daqueles que perderam familiares levados pelo "mar de lama" - sentimentos de desenraizamento, não pertencimento ao novo espaço de moradia ganham corpo e se reproduzem nas falas, expressões e sentimentos de desapropriação em relação ao próprio futuro. Esse contexto, aliado a uma nova realidade de moradia não mais no espaço rural, mas, agora no espaço urbano, morando em casas sem quintal ou em apartamentos, distantes dos vizinhos e de tudo que fazia referência a um espaço/território que lhes era importante, acentuam ainda mais esses sentimentos. 
A ideia de comunidade como vinculada a uma vivência verdadeiramente humana, permeada pela união e integração entre seus participantes, percebidos como iguais, onde há um foco no bem comum foi fortemente incorporada pela Psicologia Comunitária Latino Americana, marcada por um pensamento comunitarista, se opondo a uma visão individualista. Neste contexto, a conscientização dos sujeitos, tida como essencial à transformação social e à participação democrática, seria favorecida pelo compartilhamento de valores morais, pela vida comunitária e pelo ideal de bem comum (Prado, 2002), noções que se aproximam em muito das trazidas pelas atingidas e pelos atingidos ao se referir à vida que levavam anteriormente ao desastre. A noção de comunidade e a intervenção sobre a mesma são percebidas, na Psicologia Social e na Psicologia Social Comunitária à superação das desigualdades econômicas, tecnológicas e científicas a que os países latino-americanos se encontram.

O conceito de comunidade, que já havia sido usado para referir aos produtos mentais gerados pelas interações coletivas e, depois, foi empregado na proposta de alterar atitudes de indivíduos e possibilitar sua integração a grupos (anos 1950), ganhou força no processo de humanização ao atendimento do doente mental e em políticas públicas de desenvolvimento de potencialidades individuais, grupais e coletivas. Nos anos 1960, passa a ser visto como lócus de gerenciamento de conflitos e mudança de atitudes marcada por delimitação espacial/geográfica. No entanto, a partir dos anos 1970, adquire o caráter apresentado por Prado (2002) e Mayorga (2007) quando a crise da Psicologia Social leva a um questionamento teórico, metodológico, epistemológico, político e ético da ideia de comunidade.

Este processo inclui a incorporação de teorias marxistas que almejam a superação da exploração e da dominação, o que seria possível se as comunidades (espaço habitado por trabalhadores oprimidos) fossem convertidas à comunidade idealizada, na qual os indivíduos se vinculam ao território físico e simbólico. Se antes a comunidade era pensada como oposição ao progresso, se apresenta agora como noção utópica marcada por uma vida comum e solidária (Sawaia, 1996).

Para Freitas (1996) o conceito remete também a proposta de romper com a separação entre individual e coletivo, ao mesmo tempo em que se almeja focar na vida real e concreta das pessoas, seus cotidianos, historicizando a produção da subjetividade. As relações interpessoais e entre os indivíduos e o território são vistas como centrais à constituição dos sujeitos e também das comunidades, sendo que nestas as relações não se restringem às funcionais, mas abarcam também momentos de troca, comunhão e amor. Assim, são a um só tempo centrais à identidade dos indivíduos, ao seu sentimento de pertença e também à sua plena realização, que é fruto da inserção em um contex to em que "são todos chamados pelo nome", sendo percebidos como sujeitos autônomos e aptos a se posicionar e serem ouvidos pelos demais de forma democrática e singular. Ao ver sua individualidade e seu discurso reconhecidos e validados, o sujeito constrói a si e à comunidade, construindo também a cidade e a sociedade (Sarriera \& Saforcada, 2010).

Desse modo, temos como objetivo compreender os sentidos de comunidade construídos e acessados pelos atingidos e atingidas de Mariana/MG anteriormente ao desastre e após seu acontecimento. Almejamos analisar os efeitos do desastre por parte dos atingidos e os meios de resistência empreendidos em defesa dos territórios que ajudam a recriar o sentimento de comunidade que se mostra principalmente na manutenção do vínculo com o espaço físico devastado. 


\section{Metodologia}

$\mathrm{O}$ artigo aqui apresentado congrega resultados de diferentes pesquisas e contatos com o campo sendo que uma das autoras realiza pesquisa pós-doutoral; a outra, além de ter sido residente em Mariana e ter trabalhado no processo de assessoria técnica a pessoas atingidas, também desempenha pesquisa doutoral; e, a terceira, é supervisora/orientadora das demais.

A pesquisa de pós-doutorado teve como uma das atividades a realização de etnografia visando compreender as novas configurações relacionais e possibilidades de enfrentamento que se consolidaram neste contexto. Além da visita às duas comunidades citadas e à Mariana, o trabalho de campo incluiu entrevistas com seis pessoas atingidas (gravadas e transcritas) e a observação de atividades realizadas pela Fundação Renova (gerida pela Samarco/BHP/Billinton, responsável pelo desastre/crime) e pela Cáritas (que presta assessoria técnica aos atingidos), registradas em diário de campo.

A segunda autora mudou-se para Mariana em janeiro de 2016 para integrar a equipe de saúde mental responsável pela atenção psicossocial aos atingidos. Acompanhou as famílias atingidas em seu período inicial de transição dos hotéis para as casas alugadas pelas empresas e as dificuldades advindas dessa mudança em seus modos de vida, sobretudo, em reconhecer aquele novo lugar como sendo seu lar, lhes faltavam espaço, ar, quintal, horta. Após um período de trabalho na saúde mental, passou a integrar até início de 2018 a equipe de assessoria técnica da Cáritas em Mariana, período em que pode acompanhar de perto todos os processos relativos às negociações para reconstrução das vilas atingidas e suas lutas pelas indenizações. Atrelado às atividades de trabalho, também desenvolveu atividades de campo para sua pesquisa de doutorado, na qual investigou as vivências e os impactos que o crime da Samarco ocasionou na vida das mulheres atingidas.

A terceira autora orienta/supervisiona as demais em suas pesquisas acadêmicas, além de ser coordenadora de projeto de pesquisa que articula pesquisadoras de diferentes universidades e de grupo de extensão com o mesmo tema.

\section{Resultados e discussão}

\section{Um pézinho de árvore, andar a cavalo e a simplicidade da vida das comunidades antes do desastre}

É... tenho mais ou menos uns 24 anos que minha casa foi construída, e...fui morar ali, perto do... meu sogro, e a gente tinha um vínculo muito forte, é... Ele morava a uns 300 metros da gente, e, nossos filhos conviviam lá, conviviam com a gente, foi praticamente criado ali, é... a gente... decidiu ter uma vida assim nesse lugar porque a gente gosta da vida simples, cê entendeu, a gente podia ter optado viver na cidade, num lugar onde poderia ser mais evoluído, mas a gente decidiu morar ali porque a gente gosta dessa vida, de andar a cavalo... produzir, grande parte da nossa alimentação. É... eu tinha porco na minha casa pra gente matar pra despesa, algo que eu quisesse. [...] E... a gente era feliz, cê entendeu? Dentro da simplicidade que a gente vivia, a gente era feliz. E veio o rompimento da barragem.

(Atingido de Paracatu de Cima) 
O Rio Doce possui cerca de $853 \mathrm{~km}$ de curso d'água, sendo uma das mais importantes bacias hidrográficas da região sudeste do Brasil. As cidades que dele dependiam para o abastecimento de água, pesca, irrigação de plantações, lazer, entre outras atividades, estão impossibilitadas de fazerem uso da água do rio. Essa situação para os índios Krenaks é emblemática, pois além das atividades de pesca e plantio possuíam uma relação espiritual com o rio (Watu) considerado sagrado. O rompimento de Fundão afetou profundamente a vida de comunidades e cidades que dependiam do Rio Doce para seu sustento, subsistência, lazer e, também, afetivamente. Sendo ainda mais graves e profundos os impactos sobre comunidades tradicionais.

Nos debruçamos neste artigo especialmente sobre os impactos nas comunidades do município de Mariana-MG, regiões com poucos habitantes e uma vida muito marcada pela relação com o espaço por meio de redes de vizinhança, mas também pelo plantio do alimento. Onde imperavam o tempo da terra, as conversas embaixo de um pé de fruta e as cerimônias religiosas. Diferente da vida acelerada e impessoal das grandes cidades. Mariana, sendo um município pequeno, com pouco mais de 58 mil habitantes, para os moradores das comunidades atingidas, pequenas e rurais, é considerada uma cidade grande.

Durante a semana todo mundo espalhado trabalhando, final de semana todo mundo ia. Mas mesmo assim, os vínculo de amizade, tudo, mesmo quando a gente não tava trabalhando tava direto lá, e folga, feriado, assim, tava todo mundo lá, sempre todo mundo junto, e... eu falo assim, é uma coisa que eu... até comento sobre isso numa peça que a gente faz aqui, que eu falo assim: eu não sabia se eu gostava do Bento. Aquela rua pequena... aquela cerca de bambu, era coisa muito simples pra mim. Só que hoje eu sei, que eu queria morrer lá. [...] Quando eu vinha em Mariana aqui, ficava aqui, as vezes tava trabalhando aqui, tinha que ficar o mês inteiro aqui, mas, nos... final de semana, aí quando dava nos final de semana eu rezava pro final de semana num acabar. Porque eu queria que ele emendasse, porque eu queria ficar lá mais dias. E... aí tipo assim, eu falava que era nessa parte que a gente descobre, né? Até eu, eu ... fiz essa fala no teatro e foi do ala feminino que falou do lugar dela comigo ai eu detesto o lugar que eu moro, tal lugar, lá é muito parado, falei fala isso não minha filha. Que eu não sabia que eu gostava de Bento agora eu sei que gostava muito mais. Achava lá muito parado, mas... era minha cara mesmo... a vida da gente lá era outra coisa. [...] Aquelas coisas assim que [rindo] qual o valor que tem um toco de madeira, senta, pra gente sentar aqui... qual o valor que tem um pezinho de árvore pra gente fazer uma sombrinha... quê que é gostoso sentar debaixo de uma arvrinha, de um gramadinho...

(Atingido de Bento Rodrigues)

As conversas com os atingidos e as atingidas indicam uma percepção das comunidades que habitavam como lócus de diálogo, troca, simplicidade, harmonia, havendo certa idealização da vida no campo frente às novas possibilidades trazidas pela "cidade grande".

É tranquilo, era... um sossego, né. É... as, as coisas que que tinham lá assim de, de... vamos dizer... a, as festas, juntava bastante gente, um ano ia uma pessoa no ano seguinte ela... levava mais, e aquela coisa mesmo, um lugar muito tranquilo de... viver né, de viver... muito próximo de, de Mariana que... 22, 24 quilômetros então um lugar muito, muito próximo do, da cidade né, Mariana que é o centro, é... aquele lugar muito... tranquilo e muito... fácil pra, pra... ir lá, voltar ao mesmo tempo. Então aquele lugar muito tranquilo mesmo pra... poder morar... viver a vida, né?

(Atingido de Bento Rodrigues) 
Muitas pessoas atingidas eram nascidas nas comunidades ou foram para lá ainda muito novas e, mesmo que em algum momento tenham optado pela vida na "cidade grande", mantinham uma visão idílica das regiões e retornavam para lá em busca de descanso, dos amigos, familiares ou até mesmo de uma fruta colhida no pé.

Ah... Bento Rodriguesné, desde que eu cheguei ali aos seis anos de idade aquele lugarzinho... pequeno né, é... pessoal muito... assim, tudo unido porque era um lugarzinho pequeno que foi crescendo nesses 40 e... 47 anos foi um lugarzinho que foi crescendo, é... todo mundo melhorando suas casas... e foi aquele lugar assim.... Que, foi crescendo, é... todo mundo que, que às vezes um visitante ia lá gostava muito, a gente como morador ficava até satisfeito, não só por estar visitando diretamente a mim, mas uma pessoa que vai lá visitar um outro, um outro morador de lá, a gente via como que as pessoas falava nó que lugarzinho gostoso e realmente, era aquele lugarzinho bom de viver, sabe?

(Atingido de Bento Rodrigues)

Mesmo Bento Rodrigues e Paracatu sendo distritos do município de Mariana, observamos nas falas dos atingidos que sua identificação era com o território atingido e muito menos com a cidade, sendo muito comum falas "Eu sou de Bento" ou "Eu sou de Paracatu". Este fato pode ser observado também pelo seu não reconhecimento da vida em Mariana como sendo parte do seu cotidiano, mas como algo alheio, estranho, a "vida na cidade gran$d e$ " que não parecia em nada com a "vida simples" das comunidades destroçadas.

Assim, pra mim eu acho que... eu vou tá lá eu vou saber que... aquele lugarzinho... que era só nosso, aquele lugar pra chamar de meu.... tá lá embaixo destruído aquele lugar e o lugar que eu tô não era aquele lugar que era meu.

(Atingido de Bento Rodrigues)

A saudade da vida simples de lugarejo geram uma constante busca por recriar o sentimento de comunidade que se mostra principalmente na manutenção do vínculo com o espaço físico devastado (visitas, festas, churrascos) e na tentativa de recriar o mesmo no espaço onde será feito o reassentamento (redes de vizinhança, recriação de espaços de sociabilidade), temas sobre os quais discorreremos nos próximos itens.

\section{De Bento e Paracatu a Lavoura e Lucila: a espera pelo reassentamento}

É muito importante que a construção se pareça com o Bento antigo, que a vizinhança seja a mesma, com terra boa para plantar e tudo. Na Lavoura, tudo vai ser diferente, mesmo assim, será o nosso lugar, e, creio eu, temos que pensar dessa forma.

(Atingido de Bento Rodrigues)

Desde o rompimento de Fundão, os atingidos das comunidades de Mariana e Barra Longa que perderam suas casas e seus territórios convivem com uma série de incertezas em relação ao processo de reassentamento. Na impossibilidade de retornar ao lugar que moravam e mantinham vínculo de pertencimento, vivem em casas alugadas provisoriamente e esperam a reconstrução de suas casas em novo local. 


\begin{abstract}
Meus pais já estão com mais de 60 anos. Eles estão doidos para voltar, mas eu acredito que se acostumar com um novo lugar vai ser difícil. Lá na casinha simples deles tinha tudo. Todas as lembranças, fotos, a herança deixada pelos meus avós, foi tudo embora. Então, eles ainda têm uma certa mágoa, mas meu pensamento ainda é positivo. [...] $O$ que mais eu sinto falta é do contato que a gente tinha com o pessoal. Com certeza, quando construírem nossas casas, iremos nos reunir de novo para jogar papo fora. Hoje, nosso contato só acontece por reunião, fora disso, é muito difícil. A expectativa da população é tão grande que, nas poucas vezes em que nos encontramos, a gente sempre pergunta: nós vamos ter o terreno para morar ou não? Nos próximos meses, iremos festejar em Gesteira e fazer algumas reuniões para mostrar para o povo que estamos vivos e que não desistimos. (Atingido de Gesteira Velha)
\end{abstract}

Um dos pontos centrais no processo de reassentamento das comunidades de Bento Rodrigues e Paracatu é a premissa de que sejam mantidas as relações de vizinhança e que as comunidades reconstruídas se pareçam com as originais, destruídas pela lama. Os atingidos e atingidas desejam que as edificações das praças, igrejas, escolas, posto de saúde, entre outros equipamentos públicos, bem como, os terrenos e casas sejam similares ao que foi destruído. Tais fatos se convertem em tentativas de recuperar não só as propriedades individuais e comunitárias perdidas, mas o próprio sentimento/sentido de comunidade.

"No dia 5 de novembro, minha vida deu um pause $e$ até hoje não consigo dar o play". Essa frase, dita por uma moradora de Paracatu de Baixo, talvez seja um bom exemplo do que essa espera pelo reassentamento signifique, uma ideia ilusória de pausa, de congelamento. Contudo, sabemos que, embora, seja essa a sensação, a vida continua acontecendo, pessoas se casaram, tiveram filhos, separaram, jovens e crianças frequentam outras escolas, a distância entre os antigos e vizinhos provocou a perda ou enfraquecimento de antigos vínculos de amizade e não é possível dimensionar os significados desses processos em termos psicossociais e subjetivos quando as pessoas retornarem para as vilas reconstruídas.

Todavia, consideramos importante que as dimensões dessas mudanças, bem como, a conscientização das perdas seja discutida e trabalhada com as pessoas atingidas a fim de que suas experiências e vivências nos reassentamentos aconteça de forma mais realista e menos idealizada.

Mesmo com esses desafios, a expectativa dos moradores, sempre foi grande em ter sua comunidade e de certa forma suas vidas de "volta", ainda em junho de 2016, quando do processo de escolha do terreno para o reassentamento de Bento Rodrigues, os moradores já tinham claro o que esperavam para a reconstrução:

A maioria tem o mesmo objetivo: viver num cantinho, sossegado, na rocinha lá, com os mesmos vizinhos, todo mundo unido, do mesmo jeito. Pra você ver como a gente sente falta um do outro. Isso mostrou que, querendo ou não, a gente gostava um do outro e não percebia. A gente não percebia como a gente gostava do Bento.

(Atingido Bento Rodrigues)

Em matéria veiculada no jornal $A$ Sirene intitulada "O que queremos do velho no novo Bento”, em sua edição de número zero, os atingidos relataram, o que gostariam de ter de volta: as serenatas, escada de pedra, pé de esponjeira, os vizinhos, as igrejas, o cascalho, o banco de pedra da praça, o baú de palha, o cemitério, a praça, o lambari frito, brincadeiras na rua, cachoeiras, vida livre. 
Do mesmo modo, a comunidade de Paracatu ao escolher o terreno chamado "Lucila" para o reassentamento comunitário, buscou um local que fosse mais próximo da antiga comunidade, na tentativa de reaver seus modos de vida. Fato exposto na seguinte fala de uma atingida de Paracatu de Baixo "eu quero ter a nossa comunidade junta novamente, como era antes, com as nossas conversas e costumes".

$\mathrm{Na}$ espera que tem se arrastado há mais de quatro anos em face da morosidade das empresas Samarco, Vale e BHP Billiton intermediadas pela Fundação Renova em apresentar soluções efetivas para os reassentamentos em Mariana, cresce o sentimento por parte dos atingidos e atingidas de estar sendo expropriado do próprio futuro. Muitos diante de tal cenário, relataram ao longo do trabalho de campo desacreditar que conseguirão ter suas casas de volta e uma vida em comunidade como antes do rompimento de Fundão.

Para entender um pouco melhor sobre os efeitos produzidos pelas práticas das empresas na condução dos processos de reassentamento que acabam por fragmentar e dissipar os sentimentos de pertencimento identitário e comunitário entre os atingidos, apresentaremos aqui algumas situações por nós acompanhadas durante o trabalho de campo que corroboram com essa compreensão. Por se tratar de processos complexos e dinâmicos, elencamos aqui situações que consideramos mais significativas, como: a escolha e compra dos terrenos para os reassentamentos e discussões em torno da elaboração dos projetos urbanísticos.

\title{
Paracatu
}

\begin{abstract}
Muitas coisas, a gente participa isso aqui que tá acontecendo, participa de empresa, a gente vê realmente qual que é a intenção da empresa, isso dá uma insegurança muito grande, porque a vontade da empresa não é, não é boa. É... é enrolar, é fazer com que as comunidades levem tempo pra ser reconstruída, pra que ela não se fortaleça mais, pra que voltem poucas pessoas pra uma comunidade lá... sem as mesmas características que tinha antes né, e isso vai aumentando a insegurança da gente, da gente morar na casa da gente, é... hoje a gente mora numa casa dos outros, né... que... cê pode sonhar até ali, cê num pode planejar, aqui, e é isso.

(Atingido Paracatu de Cima)
\end{abstract}

No segundo semestre de 2016, a empresa Samarco ofertou três opções de terrenos para que um fosse escolhido para o reassentamento da comunidade de Paracatu, a escolha se deu através de uma votação. As opções de terrenos foram apresentadas às pessoas atingidas sem maiores explicações técnicas, sem um estudo ambiental mais aprofundado para levantar possíveis restrições nos terrenos (capacidade hídrica, qualidade do solo, etc.) e sem considerar, para o reassentamento, todos os núcleos familiares da comunidade de Paracatu.

As moradoras e moradores, em votação, escolheram o terreno chamado "Lucila" para a reconstrução da vila. No entanto, este terreno não comportava toda a comunidade, especialmente aquelas pessoas consideradas sitiantes - um pouco mais afastados do "núcleo urbano" do distrito que possuíam áreas maiores de terra destinadas à produção rural - mas, que estavam integrados à vida comunitária e tiverem suas propriedades igualmente destruídas. Devido este fato, foi necessário proceder a compra de outros nove (9) terrenos para abrigar todos os moradores. O processo de compra só foi finalizado em 
janeiro de 2018, no entanto, até meados de setembro de 2018, levantou-se a existência de pendências para a regularização cartorial dos terrenos. Ainda careciam de informações técnicas sobre demanda de água para criação de animais e cultivo nos novos terrenos e estudos requeridos pelos órgãos responsáveis para o licenciamento ambiental.

... meu povo ainda está discutindo o mapa que foi apresentado porque algumas ruas que cortam o Paracatu estão em sentidos diferentes. Por exemplo, a Rua Gualaxo, que é na esquerda, mudou para a direita. Entendemos que o terreno é diferente, mas essas coisas precisam ser discutidas. Conheço bem o terreno da Lucila e tenho medo dele não ter água para atender uma comunidade. Nosso Paracatu de Baixo tinha muita água para trabalhar, pescar e cuidar das criações. O mesmo não acontece na Lucila. A empresa alega que irá buscar água em localidades próximas, fazer poços artesianos e tudo mais. Mas, e se, um dia, faltar água? como faremos? [...] Eles falam que estamos em situação emergencial, mas o que estamos é, há dois anos, sem nenhuma resposta. Até quando vamos continuar desse jeito?

(Atingida de Paracatu de Baixo)

\section{Bento Rodrigues}

O primeiro projeto de urbanização que a empresa fez era muito bonito, mas, não tinha nada a ver com a gente. É muito importante que a construção se pareça com o Bento antigo, que a vizinhança seja a mesma, com terra boa para plantar e tudo. Na Lavoura, tudo vai ser diferente, mesmo assim, será o nosso lugar, e, creio eu, temos que pensar dessa forma. Eles pregam muito pela finalização do reassentamento em 2019 e ele precisa sair! Mas a gente ainda fica com dúvida se vai ser nessa data ou não, porque, se dentro de dois anos, a Renova não começou nem o desmatamento, imagina concluir tudo. Nós queremos nossas casas e queremos que elas sejam seguras, por isso, estamos agendando reuniões com os atingidos e com os demais órgãos para que nosso direito seja assegurado.

(Atingido de Bento Rodrigues)

Bento Rodrigues foi a primeira comunidade a escolher o novo terreno para o reassentamento, ainda em maio de 2016, a área escolhida chama-se "Lavoura". Na ocasião da escolha, assim como em Paracatu não foram apresentados estudos técnicos mais aprofundados sobre a área, sobretudo, estudos relacionados a qualidade da água e do solo. Para o terreno da lavoura, esses estudos são especialmente importantes, pois a área fica próxima do aterro sanitário do município de Mariana, que já há alguns anos tem funcionado como um lixão da cidade.

Mesmo sem tais estudos, seguiram os trâmites de escolha e compra do terreno. Em novembro de 2016, foi apresentada pela Renova/Samarco a primeira proposta de projeto da nova comunidade, a qual foi rejeitada pelos moradores por não conter nenhuma semelhança com a antiga comunidade. De lá para cá, a partir das reivindicações e pressões dos atingidos para ter um projeto mais condizente com as premissas que consideravam importantes para a reconstrução, aconteceram uma centena de oficinas conduzidas pelas empresas para fazer levantamento de expectativas e refazer a proposta. No entanto, vale ressaltar que: os espaços de discussão dos projetos urbanísticos somente aconteceram em 
função das pressões dos atingidos e que a participação das pessoas atingidas nessas reuniões não significa necessariamente poder de decisão e escolha. Tais questões podem ser observadas na fala abaixo:

É... quando nós passamos pelo processo de, de... é processo, é processo mesmo esse nome? Quando nós tava, não num é processo, é levantamento de expectativa, logo no início, aí... construindo como que vai ser o Bento, aquela coisa toda, isso foi citado logo de início. Que nós queríamos o Bento mais próximo que era, igual ou o mais próximo; é... o nome das ruas, que trouxesse o nome das ruas, e, os vizinhos também, permanecer a mesma vizinhança. Isso aí foi, foi... questionado no levantamento de expectativa. E isso tá pra ser feito, né. Que isso é meio difícil eles fazerem, né?

(Atingido de Bento Rodrigues)

Mesmo após o processo de escuta da comunidade por meio de reuniões e oficinas, onde os moradores expuseram suas opiniões em relação ao reassentamento, as empresas mostraram-se reticentes em atender as demandas comunitárias.

Assim como em Paracatu, ainda são nebulosas e desencontradas as previsões para o início e fim das obras. Em Bento Rodrigues o prazo para conclusão do reassentamento comunitário em cronograma elaborado pelas empresas e fixado na parede do escritório da comissão dos atingidos de Mariana é março de 2019.

Em reunião realizada em 27/04/2018 em um espaço coordenado pelo Ministério Público, intitulado "GT de Moradia" que contou com a presença das empresas Samarco, Vale e BHP Billiton, Renova, Atingidos e Prefeitura de Mariana, foram destacados que ainda existem várias pendências em Mariana para o início e conclusão dos reassentamentos. A Samarco/Renova como "solução" para tais problemas e a morosidade provocada pela ineficiência de suas próprias ações, apresentou como opção as possibilidades de compra assistida individual e recebimento de indenizações. Saídas individuais que dificultam ainda mais a concretização do reassentamento coletivo/comunitário.

Como forma de protesto e resistência contra a morosidade da Samarco/Renova em iniciar as obras de reassentamento, em 05 de abril de 2018, atingidas e atingidos de Bento Rodrigues realizaram ato fechando a MG 129 que dá acesso a outras mineradoras na região de Mariana. O ato serviu, também, como meio de chamar a atenção da mídia, pois, ao contrário do que prega a propaganda institucional realizada pelas empresas Samarco, Vale e BHP Billiton/Fundação Renova ainda existem muitos gargalos e descasos nos processos de reassentamento e de reparação acontecendo ao longo de toda a bacia do Rio Doce.

\section{Uma festa religiosa, um churrasco, um pé sujo de lama: ressignificando as comunidades devastadas}

Em meio as angústias vividas no processo de reassentamento, cada vez mais atingidos têm ocupado os antigos territórios como uma forma recriar os antigos modos de vida, reviver o sentimento de comunidade e também como uma forma de resistência. Buscam no meio dos objetos enlameados fragmentos da memória que se materializam, ajudam a contar uma história que, carregada de sentido, reafirma que sim, os atingidos de Mariana, pertencem a algum lugar nesse mundo. Nem que seja uma terra que hoje é lama, é lago, é ruína, mas também, casa, aconchego e segurança. 
E que lá fica pra nós. Igual você viu, ontem nós celebramos cá... a oportunidade que a gente tem, a gente vai pra lá mesmo, essa medalha que o pessoal deu aqui pra nós, foi um dia que a gente tava lá, eles gravaram pra nós, nós às vezes vamos, ficamos pra lá; é lógico, eu não tenho a minha casa pra ir pra lá mais, mas a casa do, do... das pessoas que tá lutando pra aquilo lá continuar sendo nosso, nós vamo pra lá, é... nós passamos bons momentos, mas nós choramos, tendeu, é pra ficar mesmo, não ficar do jeito que ela quer, porque se não fica muito fácil. Então, é nesse sentido que a gente sempre fala né, do... do, do que a gente vem construindo, e a gente sempre luta pra que seja dessa forma. Servindo pra nós, nós moradores tá ali revivendo o que nós já revivemos ali, que seja chorando, é... que seja lembrando, de, de.. de alguns momentos que vai ser construído depois do rompimento da barragem também, que acaba construindo outros momentos, momentos que a gente vai pra lá, acaba que nós ficamos na história. Eu vejo assim, que nós sem querer, nós tamos na história. História triste, mas nós tamo na história, né?

(Atingido de Bento Rodrigues)

Ir aos finais de semana para os distritos atingidos, fazer churrasco, realizar as festividades religiosas, fazer procissão, missa, festa de aniversário e casamentos é uma forma de ressignificar a experiência da devastação e o próprio sentido de pertença comunitária. Não é incomum, observarmos as pessoas aos finais de semana em Bento Rodrigues e em Paracatu, cuidando de seus terrenos, limpando o mato que insiste em crescer em meio aos escombros, colhendo uma fruta do pé para comer.

A presença constante de moradores nos territórios atingidos impulsionou a criação de alguns grupos que autonomamente se organizaram para defender e cuidar das comunidades, esse é o caso, por exemplo, do "Loucos por Bento", moradores que improvisaram em meio às ruínas de uma das casas do distrito, um espaço coletivo para cozinhar, tomar banho e dormir, quase todos os dias da semana é possível encontrar alguém no local.

É uma forma de lembrar de que ali existia uma casa, existia uma história. A tentativa de manter essas lembranças pôde ser observada por nós quando um morador nos contou que fixou um grande pedaço de bambu com uma sacola plástica branca na ponta como forma de sinalizar onde era a sua casa para que a água proveniente da construção de um dique, não encobrisse a lembrança do lugar onde passou a infância, a juventude e sonhava passar sua velhice.

Ainda tem gente morando em Paracatu. A família foi retirada... veio os filhos, a esposa, e o marido ficou lá. Não consegue adaptar aqui em Mariana... entendeu? E... num tá nem preocupado se vai ter outro reassentamento, tá levando a vida lá, entendeu. Inclusive esse moço, ele é meu cumpadre... ele andou, anda naquelas lamas pra todo lado descalço e tal. Aí ele foi no médico, porque ele tava com muita dor no estômago. Aí o médico perguntou pra ele se ele tá em contato com a lama, se ele anda descalço sobre a lama, ele saiu do médico e falou: esse médico num entende nada, eu tô com uma dor de estômago e ele perguntando se eu tô andando descalço. [ri]. Aí, fica difícil né. Aí tá lá, num sai de lá pra nada não.

(Atingido de Paracatu de Cima)

Além da possibilidade de ressignificar a experiência traumática das perdas, da casa, amigos, vizinhos, natureza, etc., a ida aos territórios atingidos permite que as pessoas tenham espaços para um convívio comunitário menos regulado pelas empresas, pois desde 
que a barragem rompeu os atingidos prioritariamente encontram-se em reuniões, que são espaços mediados e pautados pela Samarco, Vale e BHP Billiton. Seus interesses e os das empresas são contraditórios, suas demandas são diametralmente opostas à das empresas. Desse modo, as brechas que se abrem quando as pessoas insistem em frequentar as ruínas de suas casas é também uma forma de manifestar que mesmo nas maiores atrocidades realizadas pelo capitalismo, há algo que escapa ao controle e resiste.

\section{Ressignificação e Resistência}

As formas como os atingidos e atingidas tem ressignificado a noção de comunidade é também uma forma de resistir. Resistência sendo entendida aqui a partir das contribuições de Baruch de Espinosa, como parte fundante da vida humana e constituinte da vida política - como potência de vida. É a resistência ativa que possibilita aos sujeitos por meio dos afetos, experimentarem a alegria e a autonomia. Desse modo, contrapõe-se a ideia negativa de resistência como um dispositivo apenas reativo a partir de uma ordem política violada. Resistir aqui também é entendido como um movimento de produção de vida, de potência, daquilo que escapa pelas brechas impostas pela barragem e pelo controle das empresas mineradoras, é sobre aqueles e aquelas que transformam luto em luta, e que cotidianamente reafirmam a crença na vida e em um futuro melhor ao lutar contra as injustiças.

Neste escopo, a Psicologia Social Comunitária tem um importante papel a cumprir no sentido de apoiar as comunidades em seus processos de resistência e luta. Destacando que, dentre as motivações ao surgimento da Psicologia Social Comunitária no Brasil a realização de trabalhos em bairros populares, favelas e associações de bairros visando melhorar a condição de vida da população, estudando a relação entre o modo de vida do lugar/comunidade à formação do psiquismo como forma de desenvolver processos de conscientização entre os moradores (Campos, 1996). Silvia Lane aponta que a inserção de psicólogos dentro dos contextos comunitários foi incentivada pelo acesso negado a contextos institucionais, fruto do contex to nacional, marcado pela ditadura civil-militar, se tornando, a partir desta inserção fundamental compreender no contexto específico o que torna o indivíduo sujeito e o que impede sua constituição enquanto tal (Lane, 1996).

Maritza Montero ressalta que os psicólogos e as psicólogas se voltam para contextos locais e seus problemas visando favorecer o fortalecimento e desenvolvimento de comunidades, limitadas por territórios específicos (Montero, 2008), o que seria promovido pelo aumento do controle e poder por parte dos seus integrantes, do ambiente social e individual (Montero, 2004). Para a autora, a área segue sendo marcada por se preocupar com fenômenos psicossociais relativos a processos de caráter comunitário que por sua vez são marcados pelos contextos cultural e social de origem. A comunidade é um ente dinâmico formado por agentes ativos, havendo uma relação entre os sujeitos e o meio ambiente em que vivem, sendo as comunidades ao mesmo tempo âmbito e sujeito da prática psicossocial comunitária (Montero, 2008). 


\section{Considerações finais}

Nossa trajetória como psicólogas sociais comunitárias foi se construindo em torno de diversos trabalhos que tinham como foco pesquisas e intervenções que, de formas diversas, se vinculavam a uma relação entre sujeito(a)s e espaços físicos. Trabalhando com migrantes, profissionais do sexo, moradores de favelas ou outros grupos, a relação com o lugar em que as pessoas habitam e/ou trabalham, mas também como espaço de construção de redes de sociabilidade e afeto sempre se mostrou central.

Fazer psicologia comunitária é, em certo sentido, também vivenciar estes espaços, participar do cotidiano das relações, o que se torna essencial para a compreensão desses. A partir de nossas experiências de trabalho e pesquisa junto aos atingidos pela Samarco em Mariana nos interpelamos em diversos momentos sobre o que significa trabalhar na/ com a comunidade com os referenciais da Psicologia Social Comunitária, quando a mesma está em ruínas e seus membros fisicamente dispersos. Não poucas vezes nos indagamos se o que fazíamos era um trabalho de psicologia comunitária. Como falar de uma comunidade que não mais existe, salvo na memória e nas tentativas de reconstrução? Como tentar compreender os sentidos daquela comunidade para aquelas pessoas sem poder estar presente e não ver o tempo passar sob a sombra de uma árvore enquanto come uma fruta colhida do pé?

Tais questionamentos nos impulsionaram a refletir sobre a comunidade para além da dimensão espacial geográfica. Longe de desconsiderar tal dimensão como um aspecto objetivo e material onde se desenvolvem as relações humanas, a ampliação do conceito de comunidade nos permitiu visualizar os laços de sociabilidade, redes de solidariedade, trocas e as subjetividades produzidas a partir de um lugar, mas não circunscrito somente a ele.

A psicologia social ao qualificar-se comunitária, hoje, explicita o objetivo de colaborar com a criação desses espaços relacionais, que vinculam os indivíduos a territórios físicos ou simbólicos e a temporalidades partilhadas num mundo assolado pela ética do "levar vantagem em tudo" e do "é dando que se recebe". Esses espaços comunitários se alimentam de fontes que lançam a outras comunidades e buscam na interlocução da fronteira o sentido mais profundo da dignidade humana. Enfim ela delimita seu campo de competência na luta contra a exclusão de qualquer espécie. (Sawaia, 1996, p. 51)

A lama que destruiu e sujou fisicamente as comunidades atingidas de Mariana não foi suficiente para apagar o sentido de comunidade vivido pelos moradores. Ao contrário, observamos uma crescente reafirmação da pertença, muitas vezes, romantizando as memórias do antigo lugar, como extremamente harmonioso, ausente de hierarquias sociais e conflitos. Sentimentos que são alimentados pela condição provisória de vida das famílias atingidas, enquanto aguardam o reassentamento, estão em um "entre lugar", no meio do que foi e do que poderá ser.

A dimensão mais concreta dos significados psicossociais destes processos na vida dos atingidos em termos de favorecer ou não sua adaptação em um novo território somente poderá ser feita ao longo do tempo. Por hora, é necessário ressaltar a importância da presença nos territórios devastados enquanto forma de elaborar a tragédia e ressignificá-la. Reconhecê-la como uma resistência que nasceu silenciosamente entre as ruínas e potencializa a união e a força coletiva dos atingidos em suas lutas cotidianas para garantia de direitos. 


\section{Referências}

Campos, R. H. F. (1996). Introdução: a psicologia social comunitária. In Psicologia Social Comunitária: da solidariedade à autonomia (pp. 9-15). Petrópolis, RJ: Vozes.

Freitas, M. F. Q. (1996). Contribuições da psicologia social e psicologia política ao desenvolvimento da psicologia social comunitária. Psicologia \& Sociedade, 8(1), 63-82.

Halbwachs, M. (1990). A Memória coletiva (L. Léon Schaffter, Trad). São Paulo:Vértice/Revista dos Tribunais.

Lane, S. (1996). Histórico e fundamentos da psicologia comunitária no Brasil. In R. H. F. Campos (Org.), Psicologia Social Comunitária: da solidariedade à autonomia (pp. 17-34). Petrópolis, RJ: Vozes.

Mayorga, C. (2007). Otras identidades: mujeres, inmigración y prostitución. Madrid: Universidad Complutense de Madrid.

Montero, M. (2004). Relaciones entre Psicología Social Comunitaria, Psicología Crítica y Psicología de la Liberación: Una respuesta Latinoamericana. Psykhe, 13(2), 17-28.

Montero, M. (2008). Introducción a la psicología comunitaria: Desarrollo, conceptos y porcesos. Buenos Aires: Paidós.

Prado, M. A. M. (2002). A Psicologia Comunitária nas Américas: o individualismo, o comunitarismo e a exclusão do político. Psicologia. Reflexão e Crítica, 15(1), 201-211.

Sarriera, J. C. \& Saforcada, E. (2010). Introdução à Psicologia Comunitária: bases teóricas e metodológicas. Porto Alegre: Sulina.

Sawaia, B. B. (1996). Comunidade: a apropriação científica de um conceito tão antigo quanto a humanidade. In R. H. F Campos (Org.), Psicologia social comunitária - da solidariedade à autonomia (6 $6^{\mathrm{a}}$ ed., pp. 35-55). Petrópolis, RJ. Vozes.

Zhouri, A., Valencio, N., Oliveira, R., Zucarelli, M., Laschefski, K., \& Santos, A. F. (2016). O desastre da Samarco e a política das afetações: classificações e ações que produzem o sofrimento social. Ciência e Cultura, 68(3), 36-40. Recuperado de http://cienciaecultura.bvs.br/pdf/cic/ v68n3/v68n3a12.pdf

\section{LETICIA CARDOSO BARRETO \\ https://orcid.org/O000-0002-4119-1961}

Doutora em Ciências Humanas pela Universidade Federal de Santa Catarina (UFSC), com área de concentração estudos de gênero, mestre em Psicologia pela Universidade Federal de Minas Gerais (UFMG), com área de concentração em Psicologia Social e psicóloga formada pela Universidade Federal de Minas Gerais (UFMG). Realizou estágio pós-doutoral junto ao Observatório Interinstitucional Mariana-Rio Doce, vinculado ao Departamento de Psicologia da Universidade Federal de Minas Gerais (UFMG), com financiamento da CAPES/FAPEMIG. Atualmente ée professora substituta do departamento de psicologia da UFMG da área de Psicologia Social e Comunitária. Atua principalmente nas áreas de psicologia social e comunitária, direitos humanos, políticas públicas, movimentos sociais, estudos de gênero e sexualidade, com enfoque na temática da prostituição e feminismo.

Endereço: Rua viçosa 611, 31, São Pedro/Belo Horizonte, CEP 30330-160, MG.

E-mail: leticiacardosobarreto@gmail.com 


\section{DÉBORA DIANA DA ROSA \\ https://orcid.org/0000-0003-0311-6773}

Doutora em Psicologia pela UFMG onde investigou os impactos do rompimento da barragem da Samarco, Vale e BHP Billiton sobre as vidas das mulheres atingidas em Mariana/MG. Mestre em Psicologia pela UFSC. Atualmente é professora do curso de Psicologia da Faculdade Pitágoras de Venda Nova.

E-mail: ddddebora@yahoo.com.br

\section{CLAUDIA MAYORGA}

http://orcid.org/0000-0003-1728-0726

Doutora em Psicologia social pela Universidad Complutense de Madrid; professora do Departamento de Psicologia da UFMG e do Programa de Pós-graduação em Psicologia; Coordenadora do Núcleo de Ensino, Pesquisa e Extensão Conexões de Saberes na UFMG.

E-mail: mayorga.claudia@gmail.com

\begin{tabular}{|c|c|}
\hline Histórico & $\begin{array}{l}\text { Submissão: 27/09/2018 } \\
\text { Revisão: 01/11/2019 } \\
\text { Aceite: 21/11/2019 }\end{array}$ \\
\hline Contribuição dos autores & $\begin{array}{l}\text { Concepção: LCB } \\
\text { Coleta de dados: LCB, DDR } \\
\text { Análise de dados: LCB, DDR, CM } \\
\text { Elaboração do manuscrito: LCB, DDR, CM } \\
\text { Revisões de conteúdo intelectual importante: CM } \\
\text { Aprovação final do manuscrito: DDR }\end{array}$ \\
\hline Consentimento de uso de imagem & Não se aplica \\
\hline Aprovação, ética e consentimento & Não se aplica \\
\hline Financiamento & $\begin{array}{l}\text { Letícia Cardoso Barreto teve bolsa de Pós Doutorado } \\
\text { pela Capes/Fapemig } \\
\text { Processo no } 88887.131409 / 2016-00 \\
\text { Programa FAPEMIG-CAPES } \\
\text { Edital: Chamada 04/2016 - Tecnologias para a Recupe- } \\
\text { ração da Bacia do Rio Doce }\end{array}$ \\
\hline
\end{tabular}

